\title{
NORMS OF HYPONORMAL WEIGHTED COMPOSITION OPERATORS ON THE HARDY AND WEIGHTED BERGMAN SPACES
}

\author{
Mahsa FATEhi And Mahmood HaJi ShaABAni
}

Abstract. In this paper, first we find norms of hyponormal weighted composition operators $C_{\psi, \varphi}$, when $\varphi$ has a Denjoy-Wolff point on the unit circle. Then for $\varphi$ which is analytic selfmap of $\mathbb{D}$ with a fixed point in $\mathbb{D}$, we investigate norms of hyponormal weighted composition operators $C_{\psi, \varphi}$.

Mathematics subject classification (2010): Primary 47B33.

Keywords and phrases: Hardy space, weighted Bergman spaces, weighted composition operator, norm, hyponormal.

\section{REFERENCES}

[1] P. S. BouRdon, Spectra of some composition operators and associated weighted composition operators, J. Oper. Theory 67 (2) (2012), 537-560.

[2] P. S. Bourdon, Spectra of composition operators with symbols in S(2), J. Operator Theory 75 (2016), 21-48.

[3] P. S. Bourdon, E. E. Fry, C. Hammond, And C. H. Spofford, Norms of linear-fractional composition operators, Trans. Amer. Math. Soc. 356 (2004), 2459-2480.

[4] P. S. BOURDON AND S. K. NARAYAN, Normal weighted composition operators on the Hardy space $H^{2}(U)$, J. Math. Anal. Appl. 367 (2010), 278-286.

[5] P. S. Bourdon And J. H. Shapiro, Mean growth of Koenigs eigenfunctions, J. Amer. Math. Soc. 10 (1997), 299-325.

[6] J. B. Conway, Functions of One Complex Variable, Second Edition, Springer-Verlag, New York, 1978.

[7] J. B. Conway, A Course in Functional Analysis, Second Edition, Springer-Verlag, New York, 1990.

[8] J. B. Conway, The Theory of Subnormal Operators, Amer. Math. Soc., Providence, 1991.

[9] C. C. CowEN, Linear fractional composition operators on $H^{2}$, Integral Equations and Operator Theory 11 (1988), 151-160.

[10] C. C. Cowen, S. JUNG, AND E. Ko, Normal and cohyponormal weighted composition operators on $H^{2}$, Operator Theory: Advances and Applications 240 (2014), 69-85.

[11] C. C. Cowen, E. Ko, D. Thompson And F. Tian, Spectra of some weighted composition operators on $H^{2}$, Acta Sci. Math. (Szeged) 82 (2016), 221-234.

[12] C. C. Cowen And B. D. MacCluer, Composition Operators on Spaces of Analytic Functions, Studies in Advanced Mathematics, CRC Press, Boca Raton, FL, 1995.

[13] M. FATEHI AND M. HAJI SHAABANI, Some essentially normal weighted composition operators on the weighted Bergman spaces, Complex Var. Elliptic Equ. 60 (2015), 1205-1216.

[14] M. FATEHI, M. HAJI SHAABANI AND D. THOMPSON, Quasinormal and hyponormal weighted composition operators on $\mathrm{H}^{2}$ and $A_{\alpha}^{2}$ with linear fractional compositional symbol, Complex Analysis and Operator Theory, to appear.

[15] C. Hammond, On the norm of a composition operator with linear fractional symbol, Acta Sci. Math. (Szeged) 69 (2003), 813-829.

[16] C. Hammond, On the norm of a composition operator, Ph. D. thesis, University of Virginia, 2003.

[17] C. Hammond AND B. J. CARSwell, Composition operators with maximal norm on weighted Bergman spaces, Proc. Amer. Math Soc. 134 (2006), 2599-2605. 
[18] C. Hammond and L. J. Patton, Norm inequalities for composition operators on Hardy and weighted Bergman spaces, Topics in Operator Theory (2010), 265-272.

[19] P. HuRst, Relating composition operators on different weighted Hardy spaces, Arch. Math. (Basel) 68 (1997), 503-513.

[20] T. L. Kriete, B. D. MacCluer and J. L. Moorhouse, Toeplitz-composition $C^{*}$-algebras, J. Operator Theory $\mathbf{5 8}$ (2007), 135-156.

[21] T. L. KRIETE AND J. L. Moorhouse, Linear relations in the Calkin algebra for composition operators, Trans. Amer. Math. Soc. 359 (2007), 2915-2944.

[22] T. LE, Self-adjoint, unitary, and normal weighted composition operators in several variables, J. Math. Anal. Appl. 395 (2012), 596-607.

[23] P. J. NiEMINEN, Essential norms of weighted composition operators and Aleksandrov measures, Journal of Mathematical Analysis and Applications 382 (2011), 565-576.

[24] E. A. Nordgren, Composition operators, Canad. J. Math. 20 (1968), 442-449.

[25] A. E. Richman, Subnormality and composition operators on the Bergman space, Integr. Equ. Oper. Theory 45 (2003), 105-124.

[26] J. H. Shapiro, The essential norm of a composition operator, Annals of mathematics 125 (1987), 375-404.

[27] J. H. Shapiro, Composition Operators and Classical Function Theory, Springer-Verlag, New York, 1993.

[28] N. Zorboska, Hyponormal composition operators on the weighted Hardy spaces, Acta Sci. Math. (Szeged) 55 (1991), 399-402. 